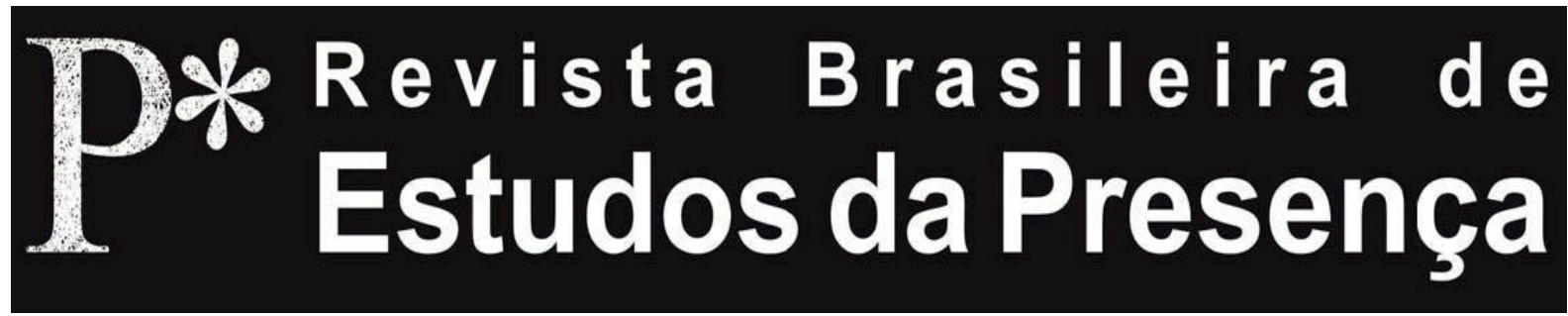

DOI - http://dx.doi.org/10.1590/2237-266025693

ISSN 2237-2660

\title{
Corpo em Cena: oralidade e etnocenologia
}

Alexandra Gouvea Dumas

Universidade Federal de Sergipe - UFS, São Cristóvão, SE, Brasil

RESUMO - Corpo em Cena: oralidade e etnocenologia - Este texto analisa processos de transmissão de conhecimentos humanos, nos quais duas formas são evidenciadas: a oralidade e a escrita. Discute-se o fato dos fenômenos cênicos serem vistos e estudados como uma variação da oralidade. Apresentam-se outras perspectivas, a partir da criação e afirmação de disciplinas que têm como objeto as práticas espetaculares, a exemplo da Etnocenologia. $\mathrm{O}$ artigo considera as particularidades e diferenciações do evento cênico em relação a outros sistemas de expressão humana. Sendo assim, o presente texto se propõe a analisar aspectos da cena no que tange ao corpo e a sua relação sensorial e comunicacional, destacando-a como um formato distinto de estruturas como a escrita e a oralidade.

Palavras-chave: Etnocenologia. Oralidade. Escrita. Espetacularidade. Memória.

ABSTRACT - The Body Onstage: orality and ethnoscenology - The analysis of the processes of human knowledge transmission, in general, reveal two ways: orality and writing. Traditionally, the scenic phenomenon is observed and analyzed as a variation of orality. With the creation and assertion of disciplines whose objects of study are spectacular practices, like Ethnoscenology, other perspectives have been developed considering, in fact, the particularities and differences between the scenic event and other systems of human expression. Therefore, this paper proposes to analyze scenic aspects regarding the body and its sensory and communication relationships, highlighting them as a different structural format, such as writing and orality.

Keywords: Ethnoscenology. Orality. Writing. Spectacle. Memory.

RÉSUMÉ - Le Corps sur Scène: oralité et ethnoscénologie - Ce texte propose une analyse des processus de transmission des connaissances humaines, dans lesquels deux formes sont généralement mises en avant: l'oralité et l'écrit. Traditionnellement, les phénomènes scéniques sont perçus et étudiés comme une variation de l'oralité. Grâce à la création et à l'affirmation des disciplines ayant pour objet les pratiques spectaculaires, à l'exemple de l'Ethnoscénologie, d'autres perspectives se développent prenant en compte les particularités et les différenciations de l'événement scénique par rapport à d'autres systèmes d'expression humaine. Ainsi, le présent article se propose d'analyser les aspects de la scène concernant le corps et sa relation communicationnelle avec le public, en la présentant comme une forme distincte des structures telles que l'écrit et l'oralité.

Mots-clés: Ethnoscénologie. Oralité. Écriture. Spectaculaire. Mémoire. 
Este texto parte do tema oralidade, já explorado largamente em áreas como a história e a literatura, tendo como foco de observação o seu conceito, suas especificidades em relação às linguagens escrita e, especialmente, a cênica. A proposta é tentar compreender os processos de construção, passagem, perpetuação e atualização de conhecimentos, colocando em evidência o sentido, a percepção e a expressão corporal envolvidos nesses sistemas.

Por ser a etnocenologia uma disciplina voltada para os estudos "[...] das práticas e dos comportamentos humanos espetaculares organizados" (Pradier, 1996, p. 21), esta se constitui, neste texto, como referencial para a abordagem dos fenômenos cenológicos. Localizada num tempo mais recente, por ser criada na década de 1990, a etnocenologia está mais próxima de uma produção de saber mais contemporâneo, que diz respeito não só ao tempo cronológico, mas também aos seus pressupostos epistemológicos com paradigmas mais maleáveis quando comparados ao período de origem do termo oralidade. Assim, na etnocenologia o conceito de corpo distancia-se do sentido dualista cartesiano, no qual corpo e mente significam substâncias distintas. Nas suas premissas teórico-filosóficas constam a pluridisciplinaridade, a consideração da diversidade e da complexidade dos fenômenos estudados. Armindo Bião localiza-a no campo da estética, no "[...] âmbito da experiência e da expressão sensoriais e dos ideais de beleza compartilhados [...]" (Bião, 2007, p. 25).

A etnocenologia não compreende as práticas corporais de forma restritiva, pois ela "[...] reconhece a complexidade e a interatividade das dimensões constitutivas do ser humano" (Pradier, 1996, p. 22). Na própria composição do termo, traz a dimensão orgânica do corpo através do radical skenos (cena), tomado, dentre os seus outros significados, "[...] para evocar o corpo humano e sua relação dinâmica com a alma" (Pradier, 1998, p. 26). Analisando sua produção, percebe-se que para a etnocenologia o conceito de corpo passa por "[...] uma imbricação do físico e do espiritual, do fisiológico e do psicológico, sua reconciliação na aceitação de suas especificidades respectivas bem como de suas interações [...]", como 
expõe Pradier (1996, p. 22) Entendendo a cena como espaço de produção e transmissão de conhecimento, pode-se inferir que os estudos etnocenológicos evocam um corpo com sua complexidade, envolvido na emissão e recepção de sentidos. Considerando a possibilidade de exploração do corpo na promoção da cena, percebe-se que os estudos acerca da escrita e da oralidade são restritivos na observação de um fenômeno espetacular.

Se na escrita, na perspectiva do espectador, a percepção humana se concentra em ver, reconhecer e decodificar os símbolos textuais, na oralidade a evidência está em falar e escutar. Já na cena espetacular, geralmente, a recepção se distribui por múltiplos canais de apreensão. Em espetáculos marcados por uma forte expressão cênica é recorrente a exploração de elementos como figurinos, iluminação e objetos, que solicitam o sentido visual, contando ainda com a percepção sonora, a exemplo dos diálogos. Os aspectos sensitivos convidam um corpo inteiro a receber estímulos nas dimensões sonoras, olfativas, táteis e visuais.

É possível identificar um corpo, seja individual ou coletivo, que se expressa através de suas múltiplas possibilidades de linguagens, numa intrínseca relação com o espectador que também dispõe de sentidos corporais mais amplos na percepção, recepção e interpretação do espetáculo. Por tal razão, seguindo um caminho contrário aos que entendem a cena como uma variação da oralidade, proponho uma distinção classificatória entre as formas de sistematização do conhecimento humano, incluindo a cena como um processo que se diferencia em relação aos campos da oralidade e da escrita.

Para tanto, faz-se necessária uma exposição acerca da oralidade. Reconhecendo na sua etimologia parte considerável do histórico do seu significado, a composição de oralidade traz o radical oris, do latim, que significa "“boca; linguagem, língua, idioma; rosto, fisionomia; abertura, orifício" (Rey, 1990, p. 132). Para o dicionário brasileiro Houaiss, o verbete oral traz o significado: "relativo à boca; que se produz na boca", "que se propaga, se transmite pela boca"; "que não é ou não está escrito; dito, realizado ou expresso de viva voz; verbal"; 
"Obs.: p.opos. a escrito"; "prova ou conjunto de provas realizadas oralmente, de viva voz, ger. em complementação à parte escrita" (Houaiss, 2009, s. p., mídia digital). Historicamente, o termo foi utilizado para designar ações relacionadas à boca. No Direito, encontram-se registros da palavra através da inscrição da lei oral ou do exame oral desde 1868. No campo da medicina foi empregada em 1805, mais particularmente na biologia com o sentido do que pertence à boca. O Dictionnaire Historique de la Langue Française (Rey, 1990) afirma que os termos 'oralmente' e 'oralidade' foram propostos "[...] em 1845 por Richard de Radonvilliers na expressão oralidade da confissão e empregada no século XX com o sentido didático de 'natureza oral', especialmente na psicanálise e na psiquiatria" (Rey, 1990, p. 132). Nos escritos registrados acerca do folclore encontra-se a utilização da palavra oralidade entre os anos de 1872 e 1877.

Tanto na sua origem etimológica quanto na sua utilização histórica, observa-se que o termo evidencia o aspecto verbal da linguagem, relacionando-o à percepção da audição e da fala, "a boca é o símbolo da voz" (Zumthor, 2005, p. 64). Por esta razão, muitos especialistas, em diversos estudos sobre a oralidade, utilizam o vocábulo para se referir aos enunciados narrados de coleta de contos populares, epopeias, recitações, mitos, lendas, romances, canções, literatura oral, poesia oral, expressões na qual a forma que se destaca é a voz. Largamente usado no campo de letras/literatura e incorporado na antropologia e na história, o termo oral/oralidade aparece como adjetivo referente a uma determinada técnica metodológica (coleta e registro de depoimentos), assim como para significar uma modalidade de conhecimento referente à memória e à poética vocal. Como exemplos, temos as denominações história oral e literatura oral como disciplinas que privilegiam a análise e reflexão de experiências não registradas, primeiramente, em escrituras, que se efetivam especialmente na experiência oral.

Em termos gerais, é preferencialmente escolhida como conceito e método na observação de práticas culturais que não utilizam a escrita como forma de transmissão de conhecimento. Acaba, assim, sendo uma definição para todas as práticas 
de transmissão e expressão de conhecimento que não utilizam os códigos das letras. Nos estudos voltados para a escrita, é comum ver oralidade como uma modalidade tão diferente da primeira que, às vezes, é colocada como uma oposição, tal as diferenças e os valores associados às duas. Assim que, tudo que não é identificado como escrito, entra no repertório da chamada oralidade.

Compreende-se que fica mais fácil reconhecer na escrita uma forma particular na sua definição, desde quando esta explora uma técnica reconhecível na sua execução associada a uma prática de leitura de seus símbolos. Já a oralidade envolve uma técnica corporal voltada à ação do falar e do ouvir. $\mathrm{O}$ próprio termo evidencia o aspecto verbal da linguagem, relacionando-o à emissão da fala e à percepção do som. Ficando restrita ao que o vocábulo anuncia, o conceito de oralidade fica subjugado à percepção humana de expressar e perceber através do falar e do ouvir, sugerindo corpos reduzidos à boca e ao ouvido.

Dessa forma, vários tipos de conhecimentos, inclusive os produzidos na dimensão cênica, acabam sendo qualificados de forma generalizante como sendo exemplo de narrativa oral ou substantivados como oralidade. Entretanto, ao observar os processos de comunicação, percebe-se que o corpo implicado nos eventos cênicos apresenta-se de forma muito mais complexa, no qual uma rede de sensações e sentidos é acionada determinando o interesse, a inserção, o aprendizado, a produção e participação de pessoas, atores/brincantes e/ou plateia/ comunidade. Neste sentido, o termo oralidade não se aplica de forma satisfatória às manifestações de caráter espetacular.

Entretanto, autores mais contemporâneos reavaliam a oralidade ampliando os seus sentidos. Transcendendo os limites da palavra, Paul Gilroy, ao analisar e discutir o conceito de diáspora no livro O Atlântico Negro, amplia o entendimento de oralidade, afirmando: "O caráter oral das situações culturais nas quais se desenvolve a música da diáspora pressupõe uma relação distintiva com o corpo" (Gilroy, 2001, p. 162). Ou seja, o seu pensamento sobre a oralidade parte de um corpo amplo, com os sentidos abertos à percepção e captação de conhecimentos e não apenas como o que fica sugerido no étimo oral. 
Paul Zumthor coaduna com este pensamento. Ao tratar da oralidade utiliza preferencialmente a denominação vocalidade e a conceitua como sendo "a historicidade de uma voz, seu uso" (Zumthor, 1993, p. 13), pois para ele este conceito engloba tanto a recepção como a percepção sensorial ou, como ele diz, compreende-se aí "um engajamento do corpo". Discute oralidade contrapondo-se a uma visão mais tradicional. Assim, afirma:

\footnotetext{
Nesse sentido não se pode duvidar de que estejamos hoje no limiar de uma nova era da oralidade, sem dúvida muito diferente do que foi a oralidade tradicional; no seio de uma cultura na qual a voz, em sua qualidade de emanação do corpo, é um motor essencial da energia coletiva (Zumthor, 2000, p. 73).
}

Nos estudos da comunicação, McLuhan coloca em oposição à oralidade um outro sistema de produção e aquisição de conhecimento humano: a escrita. Surgida posteriormente ao processo de comunicação oral, a escrita, hoje, ocupa um papel relevante na cultura. Walter Ong, estudioso da comunicação, que desenvolveu estudos a partir de McLuhan, afirma: "Nós estamos tão imersos na cultura escrita que encontramos muita dificuldade em conceber um universo oral de comunicação ou de pensamento, salvo como uma variante de um universo letrado" (Ong, 1998, p. 10). É possível estabelecer estas duas tecnologias intelectuais, oral e escrita, pela própria maneira distinta de como cada uma estrutura o pensamento. As ferramentas, as tecnologias, a organização corporal (neuropsicológica) quando diferenciadas promovem uma maneira particular do corpo e do seu funcionamento sociocognitivo na forma de elaboração e expressão de saberes, especialmente na observação de práticas tradicionais. Mesmo apresentando uma expansão do conceito de oralidade, os referidos autores não apresentam nos seus estudos a cena como objeto de análise. Partem dos objetos de evidência oral, os compreendem de forma mais ampla, porém, de certa forma, apresentam a cena, o corpo e o espaço como componentes da oralidade.

Nesta perspectiva, compreendendo o processo interativo entre linguagens e reconhecendo suas diferenças nas narra- 
tivas, o termo oralidade não se aplica de forma satisfatória aos processos de expressão espetacular. Junto às expressões escritas ou de narrativa oral, uma terceira via que compreende a encenação é recorrente tanto como forma de comunicação específica como recurso integrante na expressão do escrito e do narrado.

A forma de comunicação cênica por si é polissêmica, existe pela possibilidade e pela efetivação da conjunção e exploração de múltiplos sistemas simbólicos. Na apresentação do figurino, nas falas que são pronunciadas, no texto representado, na inserção de música ou demais sinais sonoros, na cenografia, podemos identificar elementos típicos da comunicação visual, gestual ou sonora.

A percepção do evento cênico passa por sensações e captações que evidenciam não só a escuta e a emissão da voz, como acontece na oralidade, nem apenas a visão, como acontece na leitura, mas também outros sentidos como olfato e demais sensações possíveis que atuam na relação do objeto espetacular com o espectador. Nessa perspectiva, Walter Ong, indiretamente, diferencia a comunicação gestual da oral, afirmando: "Os seres humanos comunicam-se de inúmeras maneiras, fazendo uso de todos os seus sentidos: tato, paladar, olfato e especialmente visão, assim como audição. Algumas comunicações não orais são extremamente ricas - a gestual, por exemplo" (Ong, 1998, p. 15).

A cena apresenta como marca reconhecível na sua expressão a gestualidade corporal. O gesto é uma das expressões mais significativas nas representações cênicas, em especial na sua forma teatral. Conceituado como sendo um "[...] componente da linguagem cênica que, com a voz e os jogos de fisionomia, está ligada ao corpo do ator quando ele está representando" (Pierron, 2002, p. 249), o gesto ocupa um espaço significativo a ponto de particularizar a linguagem cênica como forma de comunicação em relação à escrita e à oralidade.

Elementos espetaculares como figurino, música e ação são apresentados com carga dramática onde aspectos sonoros da fala e do som dialogam com a gestualidade de atores/ personagens envolvidos na representação. Tais elementos 
ilustram o trânsito entre as linguagens, entre gesto e palavra. Paul Zumthor, no livro A letra e a Voz, afirma: "A palavra pronunciada não existe (como o faz a palavra escrita) num contexto puramente verbal: ela participa necessariamente de um processo mais amplo, operando sobre uma situação existencial que altera de algum modo e cuja totalidade engaja os corpos dos participantes". Entendendo o gesto como indissociável da palavra, prossegue: "Na fronteira entre dois domínios semióticos, o gestus dá conta do fato de que uma atitude corporal encontra seu equivalente numa inflexão de voz, e vice-versa, continuamente" (Zumthor, 1993, p. 244). Complementando tal raciocínio, Gil confirma:

De facto, os caracteres semióticos da literatura oral são múltiplos e reenviam-nos para códigos musicais, cinésicos, paralelamente a elementos paralinguísticos que interagem com o acto performativo in praesentia: gestos e expressões faciais, factores vocais, competência dramática, audiência, nomeadamente. Apesar de excluídos do sistema linguístico, desempenham um importante papel como signos constitutivos do texto de literatura oral (Gil, 2005, s. p.).

Ao analisar narrativas medievais, Zumthor afirma:

O gesto contribuía com a voz para fixar e para compor o sentido. Muitos daqueles textos que ficaram trazem-nos fugazmente o testemunho, inscrito em sua literalidade [...]. Desde a época carolíngia, a pedagogia explora, para favorecer a memorização, a gestualidade do corpo ou das mãos e dos dedos (Zumthor, 1993, p. 244-245).

O gesto, entendido como uma das especificidades do instante cênico, passa pelas características do objeto e das sensações advindas da relação com o espectador. A mediação da cena com a sua assistência passa pelo corpo. Ao se pensar através da cena, com suas técnicas que a particularizam, criase uma forma diferenciada de organização do pensamento com o que está sendo apreciado, tanto na perspectiva de quem está em cena como de quem a assiste. A forma de comunicação cênica se reconhece, organiza-se e se efetiva no olhar do outro. Com a consciência de que são preparadas para serem vistas, as manifestações espetaculares estão ligadas diretamente ao 
público. A beleza colocada na composição de gestos serve tanto para a caracterização da personagem como também como ferramenta cênica na atração do olhar de quem a assiste.

Os elementos do espetáculo convergem num intuito de acionar a complexa rede de sentidos corporais do espectador envolvido através de uma representação rica em formas de comunicação expressas em sons, música, vozes de todo o ambiente, aspectos visuais do figurino, objetos, corpos em ação com gestos e poética vocal.

Como dito, um quesito que marca os eventos espetaculares está na relação necessária com o público. O presente espetacular se concretiza em um outro que aprecia. Esta constatação demarca um aspecto diferenciado em relação à escrita. Atualmente, o contato entre o receptor e a obra escrita se dá de uma forma mais individualizada. A organização cênica que se concretiza num momento determinado, exigindo, nos seus moldes convencionais, uma presença de quem executa e de quem assiste, faz com que o corpo de quem se envolve com o instante espetacular esteja disponível para receber informações e sensações de todas as ordens. A relação com o espectador no momento da realização espetacular possibilita que a cena tenha uma interação com o seu espectador muito mais dinâmica, considerando a escrita no seu aspecto fixo no suporte onde ela foi feita, particularmente nos livros.

Mesmo sendo a escrita portadora de uma estrutura que possibilita uma conservação de conhecimento de forma mais fixa, se ela não existe a partir da sua fruição, a sua eficiência, no aspecto da propagação do seu conteúdo, fica comprometida. Opondo-se à fixidez da escrita, a cena apresenta uma dinâmica particular, principalmente se considerarmos o espaço de diálogo com o público, agente de transformação e fixação ao aceitar ou rejeitar o que é apresentado. Muitas das representações cênicas sobrevivem ao longo do tempo por solicitar e envolver o público ao explorar dinâmicas, polissêmicas, atraentes, participativas e coletivas. Tais razões justificam-se por ser a cena o principal espaço de memória de boa parte de narrativas que existiram em formato escrito, no que tange o quesito popularidade. 
Alguns pesquisadores podem nos oferecer nos seus estudos algumas pistas para a compreensão deste fenômeno. Para Pierre Lévy,

[...] as representações que têm mais chances de sobreviver em um ambiente composto quase que unicamente por memórias humanas são aquelas que estão codificadas em narrativas dramáticas, agradáveis de serem ouvidas, trazendo uma forte carga emotiva e acompanhadas de música e rituais diversos (Lévy, 1992, p. 82-83).

Ao mesmo tempo que a cena passa a ser um importante lugar de memória de narrativas cênicas tradicionais, paradoxalmente ela é considerada como a arte do efêmero, por acontecer através de um meio que determina o tempo da sua existência: a presença de pessoas no momento da efetivação da cena, público e atores/atrizes. "De um lado, enquanto a arte, ao menos no Ocidente, tem apenas uma memória parcial, porosa, fragmentada, por outro lado, ela detém a coisa relembrada que, hoje ainda mais que antes, procura se mostrar na atualidade de um corpo, de um espetáculo" (Banu, 2005, p. 13).

Mas o evento cênico pode se fazer existir além da sua concretização física, num plano mais abstrato, transcendendo o momento cênico, ocupando o espaço da memória. É através desse mecanismo que o imaginário coletivo sobrevive. $\mathrm{Zu}$ mthor evidencia a dimensão individual da memória localizada no corpo, mesmo tendo como referência conhecimentos transmitidos entre gerações. "Nossa percepção do real é frequentada pelo conhecimento virtual, resultante da acumulação memorial do corpo" (Zumthor, 2000, p. 96).

No aprendizado do conhecimento há o processo de memorização pela associação de falas, leituras e gestos. Zumthor fala da "existência de uma lembrança orgânica das sensações, dos movimentos internos do corpo" que atuam como mecanismo de percepção e acentuado pela via do envolvimento estético. O antropólogo português Paulo Valverde ressalta a implicação do corpo e do tempo nos processos de aprendizagem. Para ele:

Esta relação com o passado através de uma memória corporal produzida no corpo foi explorada, a um nível mais geral, por Paul Connerton, que sugere que os 
grupos 'confiam a automatismos corporais os valores e as categorias que mais anseiam conservar. Eles sabem como o passado pode ser mantido em mente através de uma memória habitual sedimentada no corpo' (Valverde, 1998, p. 229).

Segundo Pierre Nora a memória é a vida, “[...] levada por grupos vivos, em evolução permanente, múltipla e multiplicada, aberta à dialética da lembrança e da amnésia, inconsciente de suas deformações sucessivas, vulneráveis a todas as utilizações e manipulações, suscetível a longas latências e a súbitas revitalizações" (Nora, 1984, p. XIX-XX).

Nessa perspectiva, a memória é compreendida como condição da existência cultural humana, "[...] ela é a propriedade de conservar certas informações, propriedade que se refere a um conjunto de funções psíquicas que permite ao indivíduo atualizar impressões ou informações passadas, ou reinterpretadas como passadas" (Silva; Silva, 2005, p. 275). É através de “[...] extraordinária ferramenta de memória e de propagação das representações" (Lévy, 1992, p. 87) que a humanidade se organiza em torno do tempo e do conhecimento. A memória se estrutura pela e para a linguagem. É pela "[...] presença ou pela falta de certas técnicas fundamentais de comunicação" que as culturas podem ser classificadas em grandes categorias (Lévy, 1992, p. 89).

Pode-se pensar a memória como uma via de transmissão de um conhecimento que se propaga e se recria. Através da percepção multissensorial e do interesse estético, um complexo sistema de memorização entra em cena, proporcionando fontes ricas de armazenamento de informações, que torna possível a reprodução da cena na memória individual de quem se relaciona com ela e também numa memória coletiva que se atualiza. A memória é assim pensada como "[...] uma aventura pessoal ou coletiva que consiste na descoberta de si graças à retrospecção" (Candau, 2000, p. 169).

A este respeito Lévy comenta:

Dramatização, personalização e diversos artifícios narrativos não são apenas destinados para o prazer de quem assiste. Eles são também condição sine qua non de durabilidade de um conjunto de proposições de uma cultura oral. Pode-se me- 
lhorar ainda a lembrança solicitando as memórias musicais e sensório motoras como auxiliares à memória semântica. As rimas e os ritmos dos poemas e dos cantos, as danças e os rituais têm, assim como os recitais, uma função mnemotécnica” (Lévy, 1992, p. 94).

A fixação do conteúdo apreciado recebe influências de natureza pessoal, interesse estético e coletivo. Ou seja, quanto mais se percebe a intensidade de envolvimento pessoal com uma informação, mais intensa é sua retenção. "Assim, os eventos ou versões de eventos que tem maior implicação sobre o sistema de representações e de crenças têm certamente mais chances de serem preservadas na memória que os eventos que só comportam pouca implicação desta ordem" (Lévy, 1992, p. 92-93).

A exposição destas reflexões surge na tentativa de se compreender a produção de conhecimento na sua relação com o tempo. Para Halbwachs o presente é transtemporal: "Os indivíduos, assim como as sociedades, sempre acomodaram as representações do seu próprio passado em função das relações do presente" (Halbwachs, 1994, p. 286). Para Joël Candau a relação conhecimento, corpo e memória "[...] resulta de uma construção memorial baseada na lenda de uma permanência 'secular' de práticas, embelezando o passado para chegar ao que Bernard Crettaz chama de a beleza do resto, sua transformação em arcaico e a fabricação de novas tradições" (Candau, 2000, p. 145-146).

A memória relacionada ao evento cênico está muito próxima do que Georges Banu aponta como o seu grande paradoxo: "[...] no momento presente do olhar se acrescenta a consciência do desaparecimento. A iminência do esquecimento aprofunda a consciência da memória" (Banu, 2005, p. 15). Ao tratar especificamente do teatro Georges Banu declara: "[...] a conservação correta é impossível porque o espetáculo não poderá jamais ser integralmente preservado como um quadro ou romance, a iminência do esquecimento aparece toda vez como um destino e um desafio" (Banu, 1987, p. 13). As expressões cênicas, por explorar uma estrutura que possibilita o esquecimento e solicitar a memória do espectador, fazem com que, mais facilmente, elas adéquam linguagens e termos 
ao contexto em que se apresenta, favorecendo a integração e o pertencimento cultural à época e ao lugar onde acontece.

Estudar eventos espetaculares à luz dos estudos da etnocenologia faz-nos perceber que a cena é um profícuo campo de estudos que podem ser organizados a partir do reconhecimento de suas especificidades. 


\section{Referências}

BANU, Georges. Les Mémoires du Théâtre. Arles: Actes Sud, rééd. 2005.

BIÃO, Armindo. Um Trajeto, muitos Projetos. In: BIÃO, Armindo (Org.). Artes do Corpo e do Espetáculo: questões de etnocenologia. Salvador: P\&A Editora, 2007. P. 25- 27.

CANDAU, Joël. Anthropologie de la Mémoire. Paris: Armand Colin, 2000.

GIL, Ana de Sousa. (Pel)os ecos da «Oratura» ou (n)a encruzilhada de uma definição. Instituto de Estudos de Literaturas Tradicionais, Universidade Nova de Lisboa, Portugal. Disponível em: <http://www.ielt.org/pagina/investigacao/lugares?id=1>. Acesso em: 10 jan. 2012.

GILROY, Paul. O Atlântico Negro: modernidade e dupla consciência. São Paulo: Editora 34; Rio de Janeiro: Editora Cândido Mendes, Centro de Estudos Afro-Asiáticos, 2001.

HALBWACHS, Maurice. Les Cadres Sociaux de la Mémoire. Paris: Éditions Albin Michel, 1994.

HOUAISS, Antonio. Novo Dicionário Houaiss Eletrônico da Língua Portuguesa. Rio de Janeiro: Editora Objetiva, 2009. 1 CD-ROM.

LÉVY, Pierre. Les Technologies de l'Intelligence: l'avenir de la pensée à l'ère informatique. Paris: La Découverte, 1992.

NORA, Pierre. Entre Mémoire et Histoire: la problématique des lieux. In: NORA, Pierre (Org.).

Les Lieux de Mémoire, vol. I. La République. Paris: Gallimard, 1984. P. XIX-XX.

ONG, Walter. Oralidade e Cultura Escrita: a tecnologização da palavra. Campinas: Papirus, 1998.

PIERRON, Agnès. Dictionnaire de la Langue du Théâtre: mots et moeurs du théâtre. Paris: Le Robert, 2002.

PRADIER, Jean-Marie. Manifesto da Etnocenologia. In: TEIXEIRA, João Gabriel (Org.). Performáticos, Performance e Sociedade. Brasília: Editora Universidade de Brasília, 1996. P. 21- 22.

PRADIER, Jean- Marie. Etnocenologia. In: BIÃO, Armindo; GREINER, Christine (Org.). Etnocenologia: textos selecionados. São Paulo: Annablume, 1998. P. 23 - 29.

REY, Alain (Org.). Le Robert: Dictionnaire historique de la Langue Française. Paris: 1990.

SILVA, Kalina Vanderlei; SILVA, Maciel Henrique. Dicionário de Conceitos Históricos. São Paulo: Contexto, 2006.

VALVERDE, Paulo. Carlos Magno e as Artes da Morte: estudo sobre o Tchiloli da Ilha de São Tomé. Etnográfica, Lisboa, v. II, n. 2, p. 221-250, 1998.

ZUMTHOR, Paul. A Letra e a Voz: a "literatura" medieval. São Paulo: Companhia das Letras, 1993.

ZUMTHOR, Paul. Performance, Recepção e Leitura. São Paulo: EDUC, 2000. 
ZUMTHOR, Paul. Escritura e Nomadismo: entrevistas e ensaios. São Paulo: Ateliê Editorial, 2005.

Alexandra Gouvea Dumas é professora da Licenciatura em Teatro da Universidade Federal de Sergipe, mestre em Artes Cênicas pela Universidade Federal da Bahia (UFBA) e doutora em Artes Cênicas, Langues et Littératures Romanes pela UFBA/Paris Ouest Nanterre La Défense.

E-mail: alexandradumas@hotmail.com

Recebido em janeiro de 2012

Aprovado em abril de 2012 